\title{
A Role Model for Academic Excellence through Socio-Economic-Cultural Factors: The Case of SAIL Schools in India
}

\author{
P K Aggarwal, Anil Sharma \\ Bhilai Steel Plant Bhilai (CG) India
}

\begin{abstract}
The Steel Authority of India Limited (SAIL) the largest public sector undertaking of India having own townships for its employees is exemplary from corporate-social-responsibility point-of-view and provides the best living conditions in India with modernized health-care and education-systems.

The SAIL-run schools in these townships give excellent academic results. Seventy six thousand children take education in 140 schools with 2274 teachers. They have been performing exceptionally well at the board examinations both in English and in vernacular-languages with the 5th, 8th, 10th and 12 th results touching $100 \%$ at one or the other location every year. The administrative factors like the government policies and their execution and institutional parameters are responsible for these achievements. But, equally contributing are some unique socio-economic and socio-cultural factors present here.

This paper establishes the contribution of such unique socio-economic-cultural factors like the family-size, the social amenities, learning environment, cosmopolitan and competitive atmosphere etc in the excellent performance of the children in SAIL townships at different locations.
\end{abstract}

\section{Introduction}

Education is the best legacy a nation can give to her citizens especially the Children and the Youth. This is because the development of any nation or community depends largely on the quality of education of such a nation. It is generally believed that the basis for any true development must commence with the development of human resources. Much then is said that formal education remains the vehicle for socio-economic development and social mobilization in any society.

The factors responsible for good academic performance across the globe are divided into two broad categories namely the administrative factors at the government and institutional levels and the socioeconomic factors. Much research has been done on the administrative factors responsible for good academic performance which include the government policies, the local administration's implementation strategies, the institutions' physical facilities and soft skills like the buildings, furnishings, laboratories, libraries, play grounds, teachers' male-female ratio, age-mix and the teaching/subject skills.

Similarly, research is also not uncommon on the effect of socio-economic factors on children's academic performance. Issues like the financial status of parents, living conditions, home-learning conditions etc have all been addressed very well around the world and a lot of improvements are also reported based on the results. Multivariate analyses have revealed that socioeconomic advantage and achievement motivation are significant mediators of academic performance in children, independent of intellectual ability. The authors of this paper realize that in addition to the commonly known socioeconomic factors, there are a number of other social and cultural factors which are little unknown to the common man and from which the world can benefit. A study of both these categories has been attempted. The study basically focuses on the situation prevalent in the townships of the steel giant of India namely the Steel Authority of India Limited (SAIL) at different plant locations, thousands of miles from each other.

\section{Literature Review}

In his book titled 'Class and Schools: Using Social, Economic, and Educational Reform to Close the Achievement Gap' (Author: Richard Rothstein) reviewed by Michael Williamson-2005 [1] it is mentioned that the issue of "Adequate Yearly Progress (AYP)" has dominated education policy debate. The one aspect is the hope that AYP will be used as a vehicle through which the federal government will finally foster quality education in America's public schools. There are others who view AYP as the tool to dismantle the traditional system of public schools. Rothstein carried out a thorough review of the social, cultural and economic issues associated with the gap in achievement among groups of students. He has also address the complex 
of cultural and social variables in limiting the opportunities of children.

Programme for International Student Assessment (PISA) is a system of international assessment of students that focuses on reading and collection of data on students, their families and institutional factors that could help to explain the differences in their academic performance. Home background, according to PISA (2000), influences academic and educational success of students and schoolwork, while socio-economic status reinforces the activities and functioning of the teachers and students.

Where a child suffers parental and material deprivation and care due to divorce or death, or absconding of one of the parents, the child's schooling may be affected as the mother alone may not be financially buoyant to pay school fee, purchase books and uniforms, such child may play truant, thus his performances in school may be adversely affected [2].

The learning environment that is full of barriers, or obstacles or distractions such as noise, gas/smoke pollutions and so on can constitute health hazards, which in turn affects or reduces students concentration or perceptual or conceptual focus to learning [3].

Anil Sharma in 2008 in his research paper titled "Education as a Major Corporate Social Responsibility in Bhilai Steel Plant" presented at the International Management Conference on 'Expanding Horizons of Business' at Indian Business Academy at Delhi India had established the contribution of industry in academic excellence [5].

Table 1a. Observations of the 140 schools in SAIL townships

\begin{tabular}{|l|c|c|c|c|c|c|c|c|c|}
\hline $\begin{array}{l}\text { Plant } \\
\text { locations }\end{array}$ & Bhilai & Bokaro & Rourkela & Durgapur & Salem & $\begin{array}{l}\text { Bhadra } \\
\text { vati }\end{array}$ & Others & Total & \%age \\
\hline $\begin{array}{l}\text { No. of English } \\
\text { Schools }\end{array}$ & 23 & 22 & 02 & 02 & 02 & 00 & 13 & $\mathbf{6 4}$ & $\mathbf{4 5 . 7}$ \\
\hline $\begin{array}{l}\text { No. of Vernacular } \\
\text { Schools }\end{array}$ & 25 & 21 & 04 & 09 & 00 & 02 & 15 & $\mathbf{7 6}$ & $\mathbf{5 4 . 3}$ \\
\hline Total Schools & 48 & 43 & 06 & 11 & 02 & 02 & 28 & $\mathbf{1 4 0}$ & $\mathbf{1 0 0}$ \\
\hline No. of Boys & 13820 & 14954 & 3171 & 2804 & 980 & 175 & 4780 & $\mathbf{4 0 6 8 4}$ & $\mathbf{5 3 . 6}$ \\
\hline No. of Girls & 14704 & 11304 & 1585 & 2694 & 685 & 172 & 4147 & $\mathbf{3 5 2 9 1}$ & $\mathbf{4 6 . 4}$ \\
\hline Wards of employees & 17718 & 7730 & 2858 & 1654 & 993 & 17 & 4192 & $\mathbf{3 5 2 6 2}$ & $\mathbf{4 6 . 4}$ \\
\hline Non Employees' Wards & 10806 & 18528 & 1898 & 3844 & 672 & 176 & 4789 & $\mathbf{4 0 7 1 3}$ & $\mathbf{5 3 . 6}$ \\
\hline Total Students & 28524 & 26258 & 4756 & 5498 & 1655 & 347 & 8937 & $\mathbf{7 5 9 7 5}$ & $\mathbf{1 0 0}$ \\
\hline No. of Male Teachers & 333 & 627 & 84 & 70 & 17 & 19 & 0153 & $\mathbf{1 3 0 3}$ & $\mathbf{5 7 . 3}$ \\
\hline No. of Lady Teachers & 418 & 227 & 54 & 117 & 37 & 03 & 115 & $\mathbf{9 7 1}$ & $\mathbf{4 2 . 7}$ \\
\hline Total Teachers & 751 & 854 & 138 & 187 & 54 & 22 & 0268 & $\mathbf{2 2 7 4}$ & $\mathbf{1 0 0}$ \\
\hline
\end{tabular}

Table 1b. The fee-structure in the SAIL- schools

\begin{tabular}{|c|c|c|c|c|c|c|c|c|c|c|}
\hline \multirow[t]{3}{*}{ Level } & \multirow{3}{*}{$\begin{array}{l}\text { Curr- } \\
\text { ency }\end{array}$} & \multicolumn{4}{|c|}{ SAIL SCHOOLS } & \multicolumn{5}{|c|}{ OTHER SCHOOLS } \\
\hline & & \multicolumn{2}{|c|}{ State Board } & \multicolumn{2}{|c|}{ Central Board } & \multicolumn{2}{|c|}{ DPS(1) } & \multicolumn{2}{|c|}{ DAV $(2)$} & \multirow{2}{*}{$\begin{array}{c}\text { MGM } \\
\text { (3) } \\
\text { All }\end{array}$} \\
\hline & & $\begin{array}{l}\text { Wards of } \\
\text { employee }\end{array}$ & $\begin{array}{l}\text { Non- } \\
\text { Wards }\end{array}$ & Wards & $\begin{array}{l}\text { Non- } \\
\text { Wards }\end{array}$ & Wards & $\begin{array}{l}\text { Non- } \\
\text { Wards }\end{array}$ & Wards & $\begin{array}{l}\text { Non- } \\
\text { Wards }\end{array}$ & \\
\hline Entry & INR & 113 & 113 & 910 & 2230 & 13320 & 22150 & 5980 & 6220 & 6670 \\
\hline Level & US\$ & 2.48 & 2.48 & 19.95 & 48.88 & 291.97 & 485.53 & 131.08 & 136.34 & 146.21 \\
\hline Secon- & INR & 361 & 361 & 2546 & 4766 & 15060 & 23890 & 10380 & 10620 & 9800 \\
\hline $\begin{array}{l}\text { dary } \\
\text { Level }\end{array}$ & US\$ & 7.91 & 7.91 & 55.81 & 104.47 & 330.12 & 523.67 & 227.53 & 232.79 & 214.82 \\
\hline
\end{tabular}

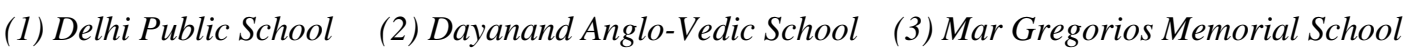

Steel Authority of India Limited (SAIL) is India's largest steel producer with a turnover of INR 48,681 crore (US \$ 9970 million) and a massive net profit of INR 6175 crore (US \$ 1265 million) in 2008-`09 [4]. It operates five integrated steel plants at Bhilai,
Bokaro, Durgapur, Rourkela and Burnpur and three specialty steel plants at Salem, Durgapur and Bhadravati. Employs 1,20,000 steel men. Produced 12.5 million tons of saleable steel in 2008-09. Presently implementing a massive expansion plan to produce 23 MT of saleable steel by 2012 . 


\section{School Education in SAIL Townships}

The company runs one hundred and forty schools within its townships at various locations with nearly seventy six thousand children studying from class one to class twelve. The schools are affiliated to both Central Board of Secondary Education (CBSE) with English medium and the state education boards with vernacular languages as medium of instruction. At a very low cost, the schools cater to the education needs of the children of SAIL employees as well as of supporting population like the security forces, employees of various government organizations (police, electricity board etc) shopkeepers, servants, rickshaw-pullers etc living in and around the townships.

It is interesting to observe from Table 1a that out of the 140 schools in SAIL townships the inclination towards vernacular schools (54.3\%) is more than English medium schools (45.7\%). The girls in these schools constitute $46.4 \%$ of the total students of 75975. Lady teachers in these schools are also matching their students counter parts with $42.7 \%$ of the total 2274 teachers. More interesting is the fact that the children of non employees or the supporting population out-number the employees' wards with $53.6 \%$ strength out of the total 75975 students.

\subsection{The Cost}

Table 1b contains information on the fee-structure in the SAIL- schools vis-à-vis other schools at Bhilai. It is evident that the SAIL-schools charge very low fees both in the State Board schools (US\$ 2.48 to 7.91 per annum only) and (US\$ 19.95 to 104.47 per annum) in CBSE schools. The private schools at the same location charge much higher fees ranging from US\$ 131.08 to US\$ 523.67 per annum.

The education in SAIL-schools is highly subsidized with US\$ 295.78 (INR 13,492) being the cost to the company per student per year.

\subsection{The Results}

The academic results for the last four years in the SAIL schools at four major plant locations are given in Table 2 to 5 .

Table 2. Bhilai Steel Plant - Bhilai (Chhattisgarh State)

\begin{tabular}{|c|c|c|c|c|}
\hline Result & $\begin{array}{c}\text { Class } \\
\text { V }\end{array}$ & $\begin{array}{c}\text { Class } \\
\text { VIII }\end{array}$ & Class-X & $\begin{array}{c}\text { Class } \\
\text { XII }\end{array}$ \\
\hline 2006 & 100 & 100 & -- & E - 86 \\
& & & & V - 84.3 \\
\hline 2007 & 100 & 100 & E -92.9 & E - 85.9 \\
& & & V -80.2 & V - 84.3 \\
\hline 2008 & 100 & 99.6 & E - 95.3 & E - 87.7 \\
& & & V -77.9 & V - 79.6 \\
\hline 2009 & 100 & 100 & E - 90.3 & E - 85.8 \\
& & & V -89.9 & V - 86.4 \\
\hline Avg. & 100 & 99.9 & E - 92.8 & E - 86.4 \\
& & & V - 82.6 & V - 83.6 \\
\hline
\end{tabular}

Table 3. Bokaro Steel Plant-Bokaro (Jharkhand

\begin{tabular}{|c|c|c|c|c|}
\hline \multicolumn{5}{|c|}{ State) } \\
\hline Result & $\begin{array}{c}\text { Class } \\
\mathrm{V}\end{array}$ & $\begin{array}{l}\text { Class } \\
\text { VIII }\end{array}$ & Class-X & $\begin{array}{c}\text { Class } \\
\text { XII }\end{array}$ \\
\hline 2006 & 100 & $\begin{array}{l}E-92 \\
V-92\end{array}$ & $\begin{array}{l}E-99.2 \\
V-88.0\end{array}$ & $\begin{array}{l}E-89.8 \\
V-73.0\end{array}$ \\
\hline 2007 & 100 & $\begin{array}{l}E-94 \\
V-95\end{array}$ & $\begin{array}{l}E-98.4 \\
V-95.0\end{array}$ & $\begin{array}{l}E-88.0 \\
V-75.5\end{array}$ \\
\hline 2008 & 100 & $\begin{array}{l}\text { E - } 95 \\
V-94\end{array}$ & $\begin{array}{l}E-97.8 \\
V-96.0\end{array}$ & $\begin{array}{l}E-87.2 \\
V-70.0\end{array}$ \\
\hline 2009 & 100 & $\begin{array}{l}E-96 \\
V-95\end{array}$ & $\begin{array}{l}E-96.2 \\
V-89.0\end{array}$ & $\begin{array}{l}E-87.4 \\
V-86.6\end{array}$ \\
\hline Avg. & 100 & $\begin{array}{l}E-94.3 \\
V-94.0\end{array}$ & $\begin{array}{l}\text { E - 97.9 } \\
V-92.0\end{array}$ & $\begin{array}{l}E-88.1 \\
V-76.3\end{array}$ \\
\hline
\end{tabular}

Table 4.

Rourkela Steel Plant - Rourkela (Orissa State)

\begin{tabular}{|c|c|l|l|c|}
\hline Result & $\begin{array}{c}\text { Class } \\
\text { V }\end{array}$ & $\begin{array}{c}\text { Class } \\
\text { VIII }\end{array}$ & \multicolumn{1}{c|}{ Class-X } & $\begin{array}{c}\text { Class } \\
\text { XII }\end{array}$ \\
\hline 2006 & 100 & $\begin{array}{l}\mathrm{E}-100 \\
\text { V }-90.0\end{array}$ & $\begin{array}{l}\mathrm{E}-98.5 \\
\mathrm{~V}-84.0\end{array}$ & $\mathrm{E}-98.6$ \\
\hline 2007 & 100 & $\begin{array}{l}\mathrm{E}-100 \\
\mathrm{~V}-92.0\end{array}$ & $\begin{array}{l}\mathrm{E}-97.5 \\
\mathrm{~V}-87.5\end{array}$ & $\mathrm{E}-100$ \\
\hline 2008 & 100 & $\begin{array}{l}\mathrm{E}-100 \\
\mathrm{~V}-96.0\end{array}$ & $\begin{array}{l}\mathrm{E}-97.0 \\
\mathrm{~V}-93.0\end{array}$ & $\mathrm{E}-99.9$ \\
\hline 2009 & 100 & $\begin{array}{l}\mathrm{E}-100 \\
\mathrm{~V}-97.0\end{array}$ & $\begin{array}{l}\mathrm{E}-97.5 \\
\mathrm{~V}-88.0\end{array}$ & $\mathrm{E}-100$ \\
\hline Avg. & $\mathbf{1 0 0}$ & $\begin{array}{l}\mathrm{E}-\mathbf{1 0 0} \\
\text { V - 93.8 }\end{array}$ & $\begin{array}{l}\mathrm{E}-\mathbf{7 8 . 1} \\
\text { V - 88.1 }\end{array}$ & $\mathbf{E}-\mathbf{9 9 . 6}$ \\
\hline
\end{tabular}

Table 5. Durgapur Steel Plant - Durgapur (West Bengal)

\begin{tabular}{|c|c|c|c|c|}
\hline Result & $\begin{array}{c}\text { Class } \\
\text { V }\end{array}$ & $\begin{array}{c}\text { Class } \\
\text { VIII }\end{array}$ & Class-X & $\begin{array}{c}\text { Class } \\
\text { XII }\end{array}$ \\
\hline 2006 & 100 & 98 & $\begin{array}{c}\mathrm{E}-100 \\
\mathrm{~V}-94.3\end{array}$ & $\mathrm{~V}-92.0$ \\
\hline 2007 & 100 & 99 & $\begin{array}{c}\mathrm{E}-100 \\
\mathrm{~V}-86.8\end{array}$ & $\mathrm{~V}-93.1$ \\
\hline 2008 & 100 & 98 & $\begin{array}{c}\mathrm{E}-100 \\
\mathrm{~V}-92.3\end{array}$ & $\mathrm{~V}-88.7$ \\
\hline 2009 & 100 & 99 & $\begin{array}{c}\mathrm{E}-100 \\
\mathrm{~V}-93.0\end{array}$ & $\mathrm{~V}-91.8$ \\
\hline Avg. & $\mathbf{1 0 0}$ & $\mathbf{9 8 . 5}$ & $\begin{array}{c}\mathbf{E}-\mathbf{1 0 0} \\
\mathrm{V}-\mathbf{9 1 . 6}\end{array}$ & $\mathrm{V}-\mathbf{9 1 . 4}$ \\
\hline
\end{tabular}

The results have been projected plant and location wise mainly to highlight the advantage of cosmopolitan atmosphere in specific cases. While the Class-V and Class-VIII exams in SAIL schools are conducted by the respective Education Departments of the plants themselves, the Class-X and Class-XII exams are conducted by the Central Board of Secondary Education and State Boards.

It is evident that the students have been doing extremely well at the lower classes with hundred percent results in Class- $\mathrm{V}$ and 94 to $100 \%$ in ClassVIII. The results of English medium schools are better. In Class-X, the results have varied from $78 \%$ to $100 \%$ but while the English medium schools have done exceedingly well in the States of Chhattisgarh, Jharkhand and West Bengal; they are not as good in Orissa. In Class-XII, the average results for vernacular schools have ranged from $76.3 \%$ to 91.4\% and for the English medium schools from $86.4 \%$ to $99.6 \%$ reflecting better performance of the English medium schools.

The most significant factor about the results is that they are far better than the national averages in case 
of English medium schools and States' averages in cases of vernacular schools. The national averages for CBSE's Class-X and XII have been $88 \%$ and $81 \%$ in 2009. The State averages for Chhattisgarh Board of Secondary Education for Class-X and XII in 2009 have been $78.35 \%$ and $74.37 \%$ respectively indicating a large difference of $4.25 \%$ and $9.23 \%$ in Bhilai Steel Plant's results. It is noteworthy that the majority of students in the vernacular schools belong to the supporting population coming from weaker economic section of the townships.

\section{Socio-Economic and Socio-Cultural Contributions}

As said earlier, the government policies, the implementation strategies of the local authorities and the other administrative factors play a very important role in the academic performance of the students. But, the socio-economic and less focused sociocultural factors prevalent in different societies play an equally important role.

The living conditions in the SAIL townships at Bhilai, Bokaro, Rourkela, Durgapur, Burnpur, Bhadravati and Salem are very different from other cities, towns and townships of India. Such miraculous performance of SAIL school students can hardly be attributed to a single major reason. But, it can be said with reasonable confidence that a number of small factors are contributing towards this miracle. The following description throws reasonable light on these socio-economic and socio-cultural contributions in the SAIL townships in academic achievements of the school students.

\subsection{Home Background in SAIL Townships}

From the PISA study, it is evident that the quality of parents and home background of a student goes a long way to predict the quality and regularity of the satisfaction and provision of a child's functional survival and academic needs. Poor parental care with gross deprivation of social and economic needs of a child, usually yield poor academic performance of the child.

Similarly, good parenting supported by strong economic home background could enhance strong academic performance of the child. This further predicts academic performance where the child is properly counseled in the choice of his/her courses and vocation that matches his mental ability, interest and capability whereas the children to the care of the illiterate mothers will find themselves roaming about the street laboring to make both the ends meet.

The striking unique-ness in the SAIL townships in this regard is the minimum status-differential amongst the residents who are all employees of SAIL. They all enjoy the SAIL wage-structure and perks which are among the best in the country. The supporting population also enjoys the patronage of the management to such an extent that even their children compete with the employees' wards.

\subsection{Learning Environment}

The environment plays very important role in the development of children. Markets and garages located near the houses have always posed a threat to students. Noise and pollution from these sources have always endangered students' life and concentration. Therefore for an effective learning and high academic performance, residences in both rural, sub-urban and urban areas should be located off zones, characterized with smoke/gas pollutions, market centers or garages as conducive learning environments stimulate learning, understanding and high perception.

All the SAIL townships are spread into large areas divided into self sufficient sectors with bazaars, health centers, schools and residential units. The spaces for all these facilities are so earmarked that they do not interfere with one another's existence. Thus, the school students live in a truly 'learning environment' with no disturbances around the residential areas.

\subsection{Physical fitness}

Results show statistically significant relationships between fitness and academic achievement, though the direction of causation is not known. While more research is required, promoting fitness by increasing opportunities for physical activity during PE, recess, and out of school time does support academic achievement.

The SAIL townships' schools promote physical fitness of not only the students but also of teachers to the optimum level. Pranaayaam (breathing exercise) is compulsory for all the students and teachers alike after the school assembly every day. Mass PTs are organized at least once a week. Games and sports are taken seriously. The students doing well in sports and games are encouraged with suitable incentives. Regular medical checkups of students in the schools are arranged. Activities like NCC, Scouts and Guides etc are encouraged.

The physique developed through so much of efforts is bound to be the home for healthy brain as well!

\subsection{Competitive atmosphere}

Life is full of competition which could be healthy and unhealthy, both ! No teacher or parent wants the kind of competition that makes children unduly anxious, that interferes with their performance and creativity, or that makes them uninterested. Healthy competition on the other hand motivates to perform as well or even better than the people we come in contact with, interact and observe. Therefore, to 
eliminate competition eliminates opportunities to learn humility and grace. Research on the negative aspects of unhealthy competition is mostly solid, but using it as a rationale for eliminating competition altogether may limit the learning and creativity of the children.

The SAIL townships are very close knit societies. People know each other very well. The families are also equally involved with each other. Therefore, the performance of one child is in the knowledge of all children and even the means to such performance are also known to others. This situation leads to very healthy competitive atmosphere resulting into efforts by almost all the children making similar efforts in an Endeavour to surpass each other.

\subsection{Cosmopolitan atmosphere}

A cosmopolitan atmosphere comprises of people from different parts of a country coming from different socio-cultural backgrounds giving rise to a common cosmopolitan culture. The advantages of cosmopolitan culture over the uni-cultural societies are multifarious.

The employees in the SAIL plants and resultant townships come from all the parts of India. The atmosphere is truly cosmopolitan and interactive. The exposure to each others' cultures is so strong that it becomes a common knowledge for all the residents of these townships.

The performance of the children of such townships in various competitive examinations which have a local bias is, therefore, above average because of mutual exposure.

\subsection{Ease of admissions and education}

The overcrowding in the Indian metros has started forcing the parents to register their children for admission even before their birth. The stressed parents can hardly afford the luxury of taking proper care of their children.

The situation in SAIL townships is entirely different. Every parent is assured of admission and good education of his children in the SAIL schools. The situation is so comfortable that many parents are not even required to visit the schools themselves at the time of admissions of their grown up children.

The education in company run schools is available at negligible price. [Refer table 1(A)].

The stress free admission and education facilities do provide an opportunity to the parents for taking the best possible care of their children who perform so well in the academics and extracurricular activities.

\subsection{Easy communication}

Communication is the process of transferring information from one source to another.
Communication is commonly defined as "the imparting or interchange of thoughts, opinions, or information by speech, writing, or signs". Communication can be perceived as a two-way process in which there is an exchange and progression of thoughts, feelings or ideas towards a mutually accepted goal or direction.

Effective communication is the strongest means of learning.

All the SAIL townships have their own network of communication. The free company telephone service is available to most of the residents. This facility contributes intensively in the academic discussions of employees' children with each other. It is not un-common to see a student talking to another for hours together trying to catch up with the studies or to excel further.

The townships have also allowed other service providers like BSNL, Tata or Airtel in the communication sector to spread their network resulting in easy and economical availability of alternative means of communication.

This situation is very largely contributing to the performance of SAIL children.

\subsection{Small families}

The advantages of small families include better financial condition of the family, better parental care and better health for the mother and the children. Thus A small Family is indeed a happy family.

It is rare to see families with more than two children in SAIL townships. The parents are enlightened and understand the advantages of small families. The children in such families, naturally, get the required amount of care and attention from their parents. Economically also the situation is very favourable. The parents are easily able to afford good education, coaching and tuitions for their children.

The results are on the expected lines. The children do very well in the exams and other activities.

\subsection{Efficient tutors - systematic coaching}

Gone are the days when tuitions were looked down upon in the society. Today, most of the parents can't think of their children's education without private tuitions or coaching. In fact, tuitions are fast becoming one of the 'essentials' in the proper development and education of children.

SAIL townships are little different in this respect that here all parents think of such a situation and arrange for appropriate tuitions or coaching for their children. The tutors are hard working and efficient. Coaching is systematic.

It is therefore no surprise that these students do so well in the board exams and competitions like JEE, AIEEE, PET, CPMT, PMT etc for admission to 
renowned professional colleges in engineering, medicine and law.

\subsection{Proactive involvement of parents in school affairs}

Across the globe, one of the strategies to bridge the gap between the schools and homes has been the inclusion of parents as educators (parent education). This involves training parents to participate proactively in their children's education by acting as 'first teachers' at home as well as participating in school settings. Parents are actively encouraged to assist their children in learning as well as to participate in developing the schools in their communities. As a result, parents and teachers work together to create a stimulating literate classroom environment and atmosphere. Parents are also encouraged to attend classroom sessions where they can witness/assess the learning process in person.

The parents in SAIL townships take active interest in the school activities of their children. The parents' teachers associations (PTAs) in SAIL township schools are very effective. They not only over see the academic activities but also encourage participation in sports, games, NCC, scouts, guides, cultural performances etc.

The positive and proactive involvement of parents provides necessary impetus to the children for doing well at the respective fronts.

\subsection{The exam fever}

With the examinations around the corner, students are bound to be under tremendous stress. But it is not just the students who are stressed as teachers and parents too face the same situation. Why do people get stressed? Adolescents are faced with the demands of their developmental tasks and that of a complex society. They need to acquire skills of adjustment to emerge into adulthood unaffected by these demands. If they lack these skills or if too many demands are made on them, they feel stressed.

Students are anxious as they are worried about whether they would be able to live up to the expectations of their peers, parents and teachers. Optimal anxiety motivates and keeps them ahead but over-anxiety disables. Anxiety is contagious and passes to other students, teachers and parents.

The exam fever grips the SAIL townships like no other virus does. The bazaars, the clubs, the social places - all bear a deserted look during the exam days. Social visits and events are postponed. Parents take utmost care that their children do not get distracted during these crucial days. It is not uncommon to see houses locked from outside with people inside.

The fever culminates into high performance of the children.

\subsection{Mothers}

A mother is a biological and/or social female parent of an offspring. Because of the complexity and differences of the social, cultural, and religious definitions and roles, it is challenging to define a mother. Mothers have historically fulfilled the primary role in the raising of children. Words would fail to describe the role of mothers in the development of their children. Unanimously would all agree that the best person to provide care, teaching and knowledge to the child is his mother ! But, availability of time has been a constraint with the mothers for the fulfillment of their dream of bringing up their children with affection, care and appropriate teachings.

Ladies in SAIL townships have all the time available on this earth at their disposal, thanks to the easily available maid servants and attached servant quarters in many houses. It is a blessing in disguise for their children as the time so available is mostly used by them looking after their children. They play responsible mothers in these townships.

Their children are blessed with good performance as a result.

\subsection{Ease of transportation}

Transportation is one of the major constrains in the fast moving life today. The time, energy and money required for commuting to the schools in big cities is quite telling on the academic performance of the students.

The SAIL townships are divided in number of sectors and each sector is normally self sufficient with bazaars, health centers and schools. Therefore, there is hardly any need for a child to travel long distances to reach his school. Even those who cover some distance, they are able to do so very easily on their bicycles because of well-built empty roads during school timings.

The saving of time in transportation to the school and stress free commuting does help the children doing better in the exams.

\subsection{Innovation -`Common Notes'}

The term innovation means a new way of doing something. It may refer to incremental, radical, and revolutionary changes in thinking, products, processes, or organizations. The goal of innovation is positive change, to make someone or something better. Innovation leading to increased productivity is the fundamental source of increasing wealth in an economy.

The parents in SAIL townships have been a little innovative too with respect to the studies of their children. A unique effort by the parents in these townships has emerged in the form of preparation of 'common notes' for their children. If Mr. X prepares 
notes on Physics, then Mr.Y gladly prepares them on Chemistry and they exchange them for each other's benefit. This cycle goes on even at micro level with one parent working on one topic in Physics and others working on other topics.

Consequentially, their children benefit from their parents un-common 'common notes'!

\subsection{Exchange of Information at Student/Parent level}

Information is truly called `power'! Exchange of information among the members of a society is vital for the development of the society as well as its sustenance. Those members who lack information are likely to lag behind in the society. But the 'exchange of information' in most societies takes a formal shape with the society-elders deciding 'what' to share with 'whom' and 'how much' etc.

But, in SAIL townships, being close-knit-familylike societies, there is much broader exchange of information including 'What to study', 'Where to find', 'How to do it', 'When to complete' etc. There is almost a complete sharing of information and material. The sharing does not stop at school! It's sharing 'beyond school' ... and also on 'beyond academics'!

Life has actually adopted different dimensions in the SAIL townships where all information available with one student or parent is accessible to all others and all efforts on the part of one are possible for all others to make because some are neighbors, some are colleagues, some are friends and so on ...! The result is obvious, the excellent performance of the students!!

\section{The Motivation to Study}

Motivation is the internal condition that activates behavior and gives it direction; energizes and directs goal-oriented behavior. According to various theories, motivation may be rooted in the basic need to minimize physical pain and maximize pleasure, or it may include specific needs such as eating and resting, or a desired object, hobby, goal, state of being, ideal, or it may be attributed to less-apparent reasons such as altruism, morality, or avoiding mortality..

One of the strongest tools in the hands of human beings to achieve desired results is goal-oriented motivation. Young children have a great ability to see the past and to learn for future. Therefore, it is easy to motivate young children with the help of past performances and future promises.

In a business family, a child is given to understand that ultimately he will operate the business regardless of his academic achievements. in steel cities, however, one sees that those who are more qualified get better status jobs with better earnings as compared to less educated ones!
This prompts even the non executive employees of SAIL townships to motivate their children to study hard to score good marks and ranks enabling them to get a seat in renowned professional institute.

\subsection{No False Courtesy}

World over, courtesy is common, which normally restricts itself to the formal behavioral aspects in human lives. A man would be considered discourteous if he does not follow the normal formalities of meeting, greeting and treating his fellow society-men. In elite societies, people make social calls with prior appointments.

But, the SAIL townships are exemplary in many respects. One of the major attributes of these townships is its informal-cordial culture! The residents are close to each other. They involve with each other's affairs. They call on each other's houses frequently. And the calls are uninformed, with no prior appointments! The social inter-mingling is a real treat to the soul!

The social interactions imbibe the children-related issues too with sharing of best academic information and practices. Thus, the 'no-false-courtesy' culture leads to inculcation of best academic environment with enviable performance at the examinations!!

\section{Contribution to knowledge}

Education is thought to be the responsibility of the government. Further, it is widely believed that public schools provide a better quality of education. Our analysis reveals that it is the industry which is the biggest end-user of the education and the industry itself, has the necessary ingredients to nurture quality education. Models, such as the SAIL Model on education, need to be worked out globally, so that industry can utilize its inherent advantages on the parameters listed in this research paper and create its own infrastructure to provide quality education. This will serve not only the industry but also the mankind in general.

Society plays a great role in supplementing the efforts of the formal education system in shaping the academic excellence of school children. There appears a need to deliberately inculcate the competitive atmosphere, the motivation to study and easy exchange of notes at student/parent level.

The economic strength of the industry may be gainfully utilized by the education system to provide quality education at an affordable cost.

There is a need to redefine the value system in the Society so that the false courtesy may not prevent the children from the free interactions; that the parents discuss education of their children during their social visits and that they devote a little more time to discuss Academics, the School, the Class-mates and Extracurricular activities with their Children. 


\section{Conclusions}

The authors believe that the paper has been able to successfully establish that the unique socio-economic and socio-cultural conditions prevalent in SAIL townships in India are contributing very significantly to the academic excellence of the children in the schools of these townships.

The atmosphere in townships of other public sector undertakings in India is not very different. The authors are convinced that major percentage of admissions to the top professional institutions in the country comes from these public sector townships.

The socio-economic-cultural parameters contributing so effectively to academic excellence in public sector townships in India can be tried to be inculcated in other parts of the world too for similar results.

\section{References}

[1] Teachers College Record Volume 107 Number 2, 2005, P.0-0; http://www.tcrecord.org;

IDNumber: 11404, Date Accessed: 11/21/ 2005 10:45:12AM

[2] A.J.Wadkar, 'Role of Home Background in Academic Achievement', 1989, Dastane Ramchandra and Co. (Pune) India.

[3] Richard C Sprinthall, 'Educational Psychology, 1987, McGraw Hill, USA.

[4] Steel Authority of India Limited (SAIL)'s financial yearbook 2008-`09.

[5] IBA International Management Conference 2008, Delhi, India. [6] http://www.wiikipedia.org/ .Access date 10 October 2009. 